\title{
Audit and Control of the Use of the Internet for Learning and Teaching: Issues for Stakeholders in Higher Education.
}

Martin Broad

University of Southampton

mbroad@soton.ac.uk

Marian Matthews

Bournemouth University

mmatthew@bmth.ac.uk

Kerry Shephard

University of Southampton

k.shephard@soton.ac.uk 


\begin{abstract}
The Internet is becoming more widely used by academic institutions to support the learning and teaching activities of students and academic staff. Whilst this is a very efficient mechanism, it is, arguably, important that there are adequate controls in place to ensure that the information is not libellous, defamatory, inaccurate, illegal or inappropriate. The interactivity of the Internet, the immediacy of access to its contents and the public accessibility to much of its information, however, do provide a different operating environment and therefore different audit and control issues arise.
\end{abstract}

This paper discusses the roles and concerns of a range of stakeholders and suggests that the control mechanisms might be failing, or might not be adequately policed in practice. A number of examples are provided where the manner in which controls are put in place do not operate effectively, or where there may be control loops that are open-ended. For each of the stakeholder groups that are identified, an account is given of the use to which the Internet is put and where regulation currently exists or may be desirable.

Keywords: Audit, Control, Learning and Teaching, Internet 


\title{
Audit and Control of the Use of the Internet for Learning and Teaching: Issues for Stakeholders in Higher Education.
}

\author{
Introduction
}

The Internet is becoming more widely used by academic institutions to support the learning and teaching activities of students and academic staff. It is also, increasingly, used to distribute information within the organisation, as well as to a wider global audience. Whilst this is a very efficient mechanism, it is, arguably, important that there are adequate controls in place to ensure that the information is not libellous, defamatory, inaccurate, illegal or inappropriate. These issues are not new and most are common to the Internet and paper based information. The interactivity of the Internet, the immediacy of access to its contents and the public accessibility to much of its information, however, do provide a different operating environment and therefore different audit and control issues arise.

This paper discusses the roles and concerns of a range of stakeholders and suggests that the control mechanisms might be failing, or might not be adequately policed in practice. A number of examples are provided where the manner in which controls are put in place do not operate effectively, or where there may be control loops that are open-ended. For each of the stakeholder groups that are identified, an account is given of the use to which the Internet is put and where regulation currently exists or may be desirable.

The desirability of any development of a formal regulatory framework is given explicit attention and is debated within the paper. This is particularly discussed in respect of whether such a framework could become more functional than is presently the case or whether self-regulation is more appropriate. It also raises further practical concerns about who is ultimately responsibility for learning and teaching material which is on the Internet, and whether universities are accountable for the way they embrace the Internet to satisfy the needs of other stakeholders in line with their strategic aims. 
The paper concludes that caution needs to be exercised about using the power of IT to over regulate the use of the Internet for learning and teaching as this could possibly hinder future development.

\section{Internet resources}

The use of the Internet to support learning and teaching activities within a university brings with it an array of issues that are currently supported through a formal and developing regulatory framework. Many of the issues may not be new to the Internet but the openness and electronic nature of the Internet does give rise to particular concerns. A recent case demonstrated that the sender of a private email can be traced by the courts and made accountable for its contents (Scott-Bayfield, 2001). Many uses of the web are protected behind password and username security devices but it will no longer be reasonable to assume that this will limit the author's responsibility. In many respects this is very different from private paper-based communication.

A related general concern is that a lack of access to resources on the Internet might be designed to ensure that the resources are directed at a particular user group but this exclusivity, whilst desirable in some contexts, also inevitably leads to lack of accountability with respect to other stakeholders. The question is one of expectation. Passwords might, for example, restrict access to an online discussion to tutor and students. If the content of the discussion, however contributes to assessment then they should also be available to an external examiner and others involved in quality assurance. Groups of users who might expect to have access to material on the Internet are naturally, most likely to raise the issue of accountability when such access is denied. Any restriction potentially permits the publisher of the information to hide behind a wall of pseudo privacy. This in turn leads to another generic issue concerning the extent that these issues of access, to Internet materials, are any different from the issues that have been with us for many years in relation to printed material. A lecturer may produce 'potentially inappropriate' learning resources for limited distribution to student users in the context of tutor-led educational use. This limited distribution may be achieved by passing printed pages directly to students or by placing the material on the 
Internet behind password and username security. The discussion that takes place within this paper focuses on the differences that do, or should exist between printed material and those that are available via the Internet.

\section{Processes and instruments of control}

In this section the processes and instruments of control that apply to users of the Internet for learning and teaching purposes are examined. For each category of user the range of uses, the regulatory framework that exists to moderate or restrict these uses and the nature and effectiveness of the responsible authority are examined. Some areas of concern will be addressed in more detail in the subsequent section, from the perspectives of key stakeholders.

Academic tutors or lecturers (academic staff) in higher education form a broad category (all three authors of this article would claim to have roles in this category, although our focus is, in each case, different and, for two of us, primarily within other categories). This breadth gives rise to an enormous range of uses and widely differing acceptance of the nature and even existence of control. Broadly speaking, academic staff use the Internet to present resources that support learning. Learning here may be in a teaching context (i.e., resources that support student learning) or in a research context (i.e. resources that support the advancement of knowledge and primarily addressed at peers). Resources might be text or images on web pages, on-line discussions between learners world-wide, computer generated simulations and mathematical models. The list is undoubtedly very long and growing daily.

The concept of academic freedom is widely distributed and appreciated in academia and it translates, in the world of the Internet, into well meaning guidance but very little direct external control at all. Most, if not all, universities provide guidelines and regulations on security; access and dissemination of information though the Internet; and guidance on legal and ethical use of computing facilities and voice networks ${ }^{1}$.

\footnotetext{
${ }^{1}$ See for example http://www.bournemouth.ac.uk/disclaimer/index.html
} 
In general these regulatory instruments, and information about them, are available to academics through publicly accessible university web pages. A wide range of national and international legislation also regulates the academic's work including legislation on Copyright (Copyright, Designs and Patent Act, 1988) and Data Protection (Data Protection, 1998). Furthermore, information about these regulatory instruments is available to academics through publicly accessible university or independent authority web pages (e.g. the Copyright Licensing Agency; CLA, 1999).

Other than offering guidance and regulations on the use of the Internet, universities have little real control over what the academic puts on the Internet. Editorial oversight may be available in principle, but in practice, university administrative staff do not have the time, or expertise, to audit all material. In addition there is also likely to be the potential for infringement of the principles of academic freedom. Many universities do acknowledge this dilemma in their information policies and strategies and attempt to find a balance between promoting the personal privacy, and academic freedom, of its staff and addressing its institutional obligations as employer and educational. The question of how to ensure that institutional legal obligations are met, while providing a reasonable amount of privacy for its users, is a growing burden for organisations. The dilemma tends to be enshrined in principle, for example within an information policy statement such as 'The University will strive to create and maintain an openness and transparency in the availability, treatment and handling of information' (University of Southampton, 2001), rather than within regulated and audited working practices.

Much has been written about the nature of academic freedom, the need for the academic profession to be unhindered by cumbersome and restrictive management and about the poorly defined nature of academic roles (reviewed for example by Kennedy, 1997). A general conclusion is that academic environments work best when free from 'checklist management' (Barnett, 1992) but Hannan and Silver (2000) identify the need to tread carefully between the two extreme options of 'diktat' and anarchy. Much of this argument no doubt applies to the potential for over-regulation of the use of Internet resources. Kennedy (1997) attempts to find 
a balance by comparing academic freedom with its counterpart, academic duty. 'The evidence suggests a kind of dissonance between the purposes our society sees for the university and the way the university sees itself. For although the freedoms necessary for teaching and scholarly work are understood and reasonably well accepted, the counter balancing obligations are vague and even obscure. Duty is to prepare; to teach; to mentor; to serve the University; to discover; to publish; to tell the truth; to reach beyond the walls; to change' (Kennedy, 1997 pp 3). Less is said about duty than freedom and, as argued by Kennedy (1997) the missing information amounts to a 'lesion in accountability'. (abid pp vii)

One slightly peculiar aspect of control over the way that the Internet is used needs to be addressed here. Peculiar because it is so novel at this stage of the development of the Internet, and slightly peculiar because it is so inefficient, ineffective and inappropriate in its present form. Some universities, more particularly some university administrators, have attempted to restrict the use of the Internet by restricting access to pornographic or otherwise undesirable websites, and restricting the publication of many four-letter words. The results of the latter are often comical and could do more harm than good. Such censorship has stifled communication at least within one institution where, for example, students were suggesting further reading of Larson (1997) but unfortunately this was censored to $\mathrm{La}^{* * *} \mathrm{n}$ (1997) with obvious frustrations ensuing.

The issues are serious, however, and relate to the desirability of any form of censorship in an academic environment committed to enquiry. The issues are also highly controversial within higher education and even the three authors of this paper do not fully agree on aspects of a censorship-free learning environment. This issue is revisited later in this paper.

If regulations and guidelines do not 'control' the Internet-publishing activities of academics, does anything? It is arguable that self-regulation provides an immediate and effective natural control. Self-regulation, of course, is entirely consistent with the principles of academic freedom. A profession that has at its core a commitment to principles of personal freedom, 
natural justice and fair play is not entirely dependent on an external control to ensure appropriate use of its professional resources.

Academics who have been accepted into the profession will have demonstrated their commitment to a range of professional values. This commitment will be constantly challenged and honed by the process of peer-review. Peer-review works at many levels including interactions between tutors working in teams to support learning, the activities of peers as external examiners for taught and research-based programmes of study and the activities of peers in external and internal quality review processes. Few academics would deny the potential of peer review to ensure that learning resources, in general, are both adequate and professionally appropriate. (But not necessarily meeting the aspirations of all stakeholders in education, as this is peer review in relation to the values of the profession, rather than 'auditing' in relation to external regulation and values). The professional consequences of repeated adverse peer review are extremely severe. Few would deny that, in practice, the peer review process is not able to scrutinise all, even most, learning material placed on the Internet. It is a blunt instrument for control and works primarily, in the context of learning and teaching, at the level of the reputation of the academic (in relation to an individual's work) and of the reputation of the department or institution (in relation to institutional and departmental audits of teaching and research quality) rather than at the level of an individual piece of work.

There is a gradual movement to formalise these self-regulatory processes. Institutions provide increasingly precise guidelines on the operation of monitoring and review processes within their departments. They have worked with the CVCP (Committee of Vice Chancellors and Principles - Now University $U^{2}$ ) and HEFCE (Higher Education Funding Council for England $^{3}$ ) to develop and use a wide range of good practice guidelines, surveys of practice and codes of conduct. These attempt to ensure reasonable and consistent use of, as examples, external examiners, provision of equal opportunities, functioning of consultancy and many other aspects of the operation of higher education. In particular, HEFCE, working with the QAA (Quality Assurance Agency), have developed institutional and departmental

\footnotetext{
${ }^{2}$ http://www.universitiesuk.ac.uk
} 
quality assurance processes to the point where 'quality scores' have become a serious descriptor of the quality of HEls (Higher Education Institutions). Competition between HEls for limited financial and other resources ensures that quality judgements are taken very seriously, both by institutions themselves and by a range of stakeholders (HEFCE, 1999a). Most recently the formal processes of peer review and evaluation have become the responsibility of internal institutional quality-review rather than dependent on external intervention. Peer review of learning resources is likely to strengthen as a consequence despite the QAA label of the 'lighter touch'. (QAA, 2001).

The academic profession is not, necessarily, a bystander in this process. By tradition, professionalism in higher education has been the prerogative of subject-based professional bodies. Their role continues but has been challenged by the new Institute for Learning and Teaching (look for ILTM after the names of this article's authors). The ILT aims to represent the views of professional 'supporters of learning' in higher education and carries a responsibility to safeguard the reputation and professionalism of its practitioners. It acts as an accreditor of the values and experience of practising university teachers and of the training courses that are being developed for new members of staff. Self-regulation to professional standards has been a feature of academic life in the UK for many years, but perhaps less will be left to chance in the future.

There is no doubt that students also have a role to play in auditing and controlling Internet resources provided by their tutors. Indeed as the primary consumer of the resources, students are in a good position to at least scrutinise the materials. Whether they are in a position to identify errors and judge how appropriate the resources are will depend on the circumstances, but there is no doubt that today's fee paying, and often self-financed students, have the power to respond. One avenue for this reaction is via anonymous evaluation of the quality of learning resources, as many universities currently undertake through student evaluation questionnaires. QAA intervention ensures that the student voice is heard and is increasingly acted upon. Students also are represented on course boards and committees that generally

\footnotetext{
${ }^{3}$ http://www.hefce.ac.uk
} 
exert influence on tutors by peer review processes. Many academics would identify a trend in higher education from teacher centred to student centred learning. As students develop as 'collaborators' in the learning process (Laurillard, 1994) their input into the auditing process is likely to become increasingly acceptable, even welcomed, by their tutors.

Students are, of course, also users of the Internet. Students use the Internet as a vehicle for submitting their assignments, for demonstrating the achievement of adequate key skills in C\&IT and for all manner of communication. Student work is, at least theoretically, highly moderated. Academic staff are likely to read the work for assessment or feedback and in many circumstances student work is available to other students for peer-review. No doubt some work does remain unread and unchallenged, but, in academic settings, this is likely to be in the minority. Some issues arise.

Student work, unless protected by password and username security, is more open 'on the Internet' to uninvited readers, than it would be in print. In addition, students are not necessarily initiated into the academic profession, with its professional values and selfregulation, so their work could, potentially, be more inclined to be inappropriate in some way. From a legal and stakeholder perspective however, student work is unlikely to be particularly controversial, as long as it is clearly identified as student work. Even the, relatively, highly structured laws on copyright impose less restraint on student activity than they would on other educational activity. UK copyright legislation has substantial exceptions for materials for 'private study' and these 'fair-use' exceptions are even more generous in the USA. For these, and related reasons, feedback on student work, by academic staff, is traditionally likely to focus on the academic nature of the work and not be particularly bound by regulatory frameworks that theoretically apply. In effect a student's freedom to express him or herself is even greater than that of the academic staff member.

On the contrary, university management and support staff, are most likely to feel the brunt of potential regulatory controls over the use of the Internet. This group of staff are responsible for identifying important legislation, engaging academic colleagues in discussion about its 
application in an academic setting and establishing the regulatory framework that is promoted within the institution. Of all groups in the academic world this group is most likely to know the correct ways to use the Internet and, possibly as a consequence, are likely to use it in the least imaginative ways. In particular this group is starting to use the Internet as an alternative, and cheaper way to publish information. Policies, strategies, calendars, agendas and minutes of meetings, prospectuses, course and programme information and much besides is, nowdays, routinely available on the Internet, and less likely to be available in print. From this two potentially serious issues arise.

First, much of this information would have a relatively restricted distribution in its printed version, but now has a relatively unrestricted distribution in its Internet version. Of course restriction is possible via IP address authorisation but this is not as widely used as is perhaps advisable. Second, the process of putting material onto the Internet is almost certainly different from the previous process of preparing and distributing printed material. If the information is both correct and appropriate then this 'freedom of information' has to be for the general good. If these new processes yield either inappropriate material or errors then there may be problems ahead. An example is available from an Australian university where many academics, accustomed to exercising autonomy with respect to developing and delivering materials, openly resisted the role that the IT Directorate assumed in deciding where learning resources would be provided (McMurray and Dunlop, 1999). 'The manner in which these decisions were taken was interpreted by some staff as signalling a shift in university governmentality from one of supporting a culture of learning, teaching and research to one which is setting off down a path of hyper-competitiveness where technologisation and globalisation become the driving forces' (McMurray, 2000). This example could be interpreted in a number of ways. Here it is used to highlight changing interactions between academic and other staff that are occurring as a result of wider use of the Internet for learning and teaching.

\section{Discussion}




\section{Personal and corporate responsibility}

An important consideration, in relation to the use of the Internet for learning and teaching purposes, is the likely consequence to individual users of infringements to regulatory instruments. If, for example, an academic places defamatory material on the Internet then the university, as an Internet Service Provider (ISP), may hide behind a claim of 'common carrier' protection (Flint, 1998) and thus seek recourse from the academic. This point, however, is not at all clear. The decision in Lawrence Godfrey v Demon Internet (1999) confirmed that the hosting of a discussion forum, and thus posting messages, was an act of publication as understood by English Law. Therefore the access provider was not simply the owner of an electronic system permitting the transmission of messages (Strowel, 2000) and was therefore responsible for its contents. Nevertheless, the question remains whether an ISP can be reasonably obliged to clean up all discussion groups in the event of complaints from third parties and even if steps are taken to pre-empt this then problems can emerge as outlined above in the $\mathrm{La}^{\star \star \star} \mathrm{n}$ debacle.

The situation is further complicated by a duty to disclose private information about originators of emails where a libellous comment has been made. Whilst the ISP itself would not be liable for the information transmitted within the email (Scott-Bayfield, 2001), there is a fine line to tread between an email that is transmitted to a wider internal audience and an internal discussion forum.

\section{Confusing regulations}

In the previous paragraph the nature of personal and corporate responsibility was considered. The related concern is the extent to which the lack of clarity about what is an allowable, or desirable, use of the Internet is inhibiting its use for learning and teaching. A single example will be developed; that of copyright. It is true, for example, that the UK does have extensive legislation that attempts to regulate the nature of copyright as it applies to literary, dramatic, musical, artistic, sound, film, broadcast and cable transmission, and 'published edition' material. Interpretation of the legislation is supported by extensive documentation and, in the UK, the Copyright Licensing Agency. Extensive problems arise, however, as many of the 
resources used to support learning and teaching transform from a text or analogue format into a digital, and in-particular, on-line format. In no sense is the law clear on a whole range of Internet-related issues that have a daily impact on the use of the Internet in universities. The issues for students, who might wish to submit assignments, containing digital copies of resources for comment, on CD or via the Internet, have been considered by Shephard (2001). The issues that relate to the copyright and other intellectual property rights of the institution have been considered by Charlesworth (1997) as a contribution to a conference organised by the UK's Joint Information Systems Committee; 'Facing the Legal Challenges of Providing Internet Access in HEls'.

The legislation is due to be updated in the near future as a result of a long awaited EU Directive on the 'harmonisation of certain aspects of copyright and related rights in the information society'. (EU, 1999). The aim is to create a 'general and flexible framework in order to foster the development of the information society in Europe' (Flint, 2001). The extent to which new legislation will be compatible with existing UK legislation and that of other countries, with which we maintain reciprocal copyright agreements, remain to be seen.

The situation is almost inevitable, considering the rate at which the Internet, and its use to support learning, has developed. The consequence of this situation, however, is variable. Some users tend to interpret the lack of clarity as lack of regulation and make great, but potentially illegal, use of the Internet. Others make a more cautious interpretation and use the Internet for considerably less that they might. The situation certainly contributes to the highly variable adoption of IT by the UK's universities and should be a significant concern to all stakeholders in higher education.

\section{Disabilities and widening participation}

Consideration should be given to the role of the Internet in relation to the significant measures that are designed to achieve widening participation in higher education. In this section, questions are raised that concern a university's ability or desire to utilise the Internet to deliver maximum benefits from the funding provided. The role the Internet plays in the design and 
delivery of appropriate learning and teaching materials is considered and the degree to which a range of social organisations have a role in ensuring a collaborative framework to achieve standards of 'best practice' and accountability is reviewed.

Education and Skills Minister Margaret Hodge recently ${ }^{4}$ reaffirmed the Governments commitment to the concept of Summer Schools providing 5,500 young people with the opportunity to experience a taste of University life. 'We want to achieve a $50 \%$ participation for the under 30's by 2010 through the introduction of new Foundation Degrees which incorporate opportunities to combine study and employment'. Furthermore, the Special Educational Needs and Disability Act 2001 will be in force by September 2002. This covers both pre and post 16 education, and amends certain sections of the Disability Discrimination Act 1995 to protect those classified disabled by the original Act. The new law affects all education, training and the provision of student services such as leisure facilities, catering, library but does not specifically mention learning technologies or the Internet. The legislation does, however introduce the concept of 'adjustments' for the disabled, 'requiring educators to pre-determine fundamental issues regarding their academic disciplines and the methods used to access and deliver these' (Corlett, 2001). It must be assumed that this will impose some increased control over the acceptability, suitability and design of Internet based learning materials. Many examples of likely developments are described within the Web Content Accessibility Guidelines ${ }^{5}$ (WCA, 1999). These are intended for Internet content developers and those who develop authoring tools. They cover accessibility principles and design issues as well as physical access concerns. Guidelines encompass all user agents whether desktop browser, voice browser or mobile phone and seek to encourage the use of multimedia content within the framework. Content developers should, for example, use an authoring package that facilitates pronunciation or interpretation of abbreviated or foreign text, thus enabling speech synthesizers and braille devices to automatically switch to the new language. In addition, guideline 7 of the WCA states that a developer should 'ensure user control of time sensitive content changes and thus ensure that moving blinking, scrolling, or auto updating pages may be paused or stopped'. Users with cognitive or visual disabilities may be unable to read

\footnotetext{
${ }^{4}$ The Times Higher Education Supplement, June 15, 2001
} 
moving text quickly enough or at all, the movement causes distraction so that the rest of the page becomes unreadable. People with physical disabilities might not be able to move quickly or accurately enough to interact with moving objects. Thus an effective user agent requires a mechanism within a script or applet to allow users to freeze moving content and updates. The guidelines are extensive and will require radical rethinking of the current mechanism for the development of learning resources if they are to be broadly applied.

The 'widening participation ${ }^{6}$ ' initiative requires special attention as it is of significant concern for a wide range of stakeholders in HE. This relates, not to inappropriate or illegal use of the Internet, but to the lack of appropriate use of the Internet. Again the issue relates to the expectations of stakeholders. Many see the use of technology in higher education, particularly the use of widely distributed Internet resources, as a necessary tool for addressing many of the problems, present and anticipated of $\mathrm{HE}$, particularly in teaching greater numbers and more diverse range of students.

The problem base is broad. Universities have been seen as elitist institutions that attempt to protect the quality of provision by maintaining exclusivity of access. UK HEl's are largely funded from the public purse and this elitism is being challenged with significant government programmes designed to increase participation in $\mathrm{HE}$; to widen access to $\mathrm{HE}$ to social groups at present poorly represented; to promote the ethos of lifelong learning; to increase the costeffectiveness of $\mathrm{HE}$; and to promote equal opportunities for a wide range of student groups.

Just about all groups in society have an interest in the success of this ongoing process and are therefore stakeholders. The interest may focus on improvements in cost-effectiveness or the long-term competitiveness of the UK economy. Whatever the interest, it is significant that the role of technology is seen by many as central to the process of change, and it must deliver these goals. Many have argued this case but perhaps most effective was Daniel (1996) who primarily based his experience on the UK's Open University. 'New technologies, most notably the Internet and world wide web, may provide superior ways of creating

\footnotetext{
${ }^{5}$ available at http://www.w3.org
} 
academic communities' (Daniel, 1996, p 17). The use of Internet resources have been seen as crucial to the operation of equal opportunity policies; for example by providing learning resources accessible to disabled students. A similar case is often made for resources to support lifelong learning and widening participation via flexible delivery of distance learning. A significant element of the development of cost effectiveness involves the use of Internet resources to deliver high quality education to increasingly large groups of students. Investments in computer assisted assessment are just one way that cost effectiveness is being promoted (Sangster, 1992)

Stakeholder concern is being expressed in a variety of ways. The most direct is via government funding which increasingly is being tied to stakeholder interests in the activities of $\mathrm{HE}$, such as funding to support widening participation, quality enhancement (e.g. the Teaching Quality Enhancement Fund; HEFCE, 1999b) and the development of human resources (HEFCE, 2000). The latter, for example, specifically, addresses the need for academic staff in HE to receive training and support for the use of C\&IT to promote learning. There is no doubt that the 'Government' as a key stakeholder in HE, and a significant representative of a wide range of other stakeholders, does have some ability to control the use of the Internet for L\&T. Financial control is powerful and has its effect via all aspects of university management.

Stakeholders also have other influences. For example the widely documented Dearing report $^{7}$, commissioned by the Secretaries of State for Education and Employment in England, Wales, Scotland and Northern Ireland with bipartisan support has had a significant impact on a wide range of developments in HE since its publication in July 1997.

A key issue for us, however, is to consider not just the aspirations of stakeholders to control the use of the Internet for L\&T, nor indeed only the mechanisms of control; we should attempt to address the consequences of these interventions. It is clear that stakeholder concern does find its way back to academics. Many, undoubtedly, feel pressurised into using technology.

\footnotetext{
${ }^{6}$ http://www.hefce.ac.uk/pubs/hefce/2001/01-29.htm
} 
The real concern here is that many feel that they are being pressurised into using technology in situations for which there is often no clear rationale or proven advantage. Indeed, Surry (2000) suggests that many view the general area of 'computer-based instruction' as a threat to their academic freedom and autonomy. The situation is very real and has been identified for some time. Indeed the Dearing report made it clear that UK institutions in general, and academic staff in particular, were not sufficiently engaged with learning technologies for higher education to derive many of the benefits that were generally felt to be possible with more widespread use of technology. Stakeholders clearly need access to more than the purse strings to effectively control this central facet of higher education. Whether this represents an essential strength of academia, or a fundamental weakness, probably depends on your personal views on the role of higher education.

\section{Conclusion}

A number of issues have been highlighted in this paper. These suggest that different stakeholders of higher education may have different perspectives of the way in which regulations that govern the use of the Internet for learning and teaching are interpreted and desirable.

The current regulatory system that has evolved has led certain stakeholders to strictly interpret guidelines, creating the potential to stifle any innovative use of the technology. There are also questions about whether the developers of learning and teaching materials have the ability, need or desire to use the technology to help meet significant broad aims such as widening participation and opening up higher education to a more diverse range of students. The imposition of a strict bureaucratic regulatory framework might undermine existing academic freedom but there are also doubts about the effectiveness of professional selfregulation.

\footnotetext{
${ }^{7}$ The National Committee of Inquiry into Higher Education, 1997 at http://www.ncl.ac.uk/ncihe/index.htm
} 
It is clear that stakeholders in higher education have great expectations about the potential of the Internet to deliver learning resources in the future. The regulatory frameworks that might allow audit and control of this use are developing rapidly, and to a large extent developing from existing regulatory instruments that have evolved in the era of paper-based learning resources. Concepts such as peer-review, professional values, professional self-regulation have co-evolved with copyright, libel and contract law into a generally workable system that is currently outpaced by the rapid development of the Internet.

An inevitable temptation is to use the power of IT to audit and control the way that IT is used in learning and teaching. There is little doubt that IT is, or will be, powerful enough to provide this degree of control. Few would doubt the data-storing capacity of tomorrow's computers, nor the extent to which Internet traffic could be intercepted, interrogated and modified to filter out inappropriate, undesirable, libellous, defamatory, inaccurate or illegal material. Of course the control would never be perfect, and clever, particularly deliberate, infringements of the regulatory code will always find a way through. The really important question is whether or not such control is necessary or desirable. A single example illustrates both the dilemma and the lack of consensus on the issue. Should universities restrict the access of staff or students to certain socially-undesirable websites? Websites that incite racial hatred or encourage and portray paedophilic acts are illegal and not in question here. Many other sites, such as those containing indecent language or pornography, are less extreme but still undesirable. The authors of this article have the following, very different views.

'There is no place for censorship within higher education for either staff or students. National and international legislation makes some resources illegal. To go further and deny access to socially-undesirable resources, or inhibit informed debate about them, would require a censor to define the undesirability of otherwise legal material. Where would the censor draw the line? Would we restrict political debate; would we inhibit commentary on racial or gender prejudice; would we deny the link between HIV and aids? Who would the censors be and who would chose them? The role of higher education is to explore beyond the walls, not within them.' 
'A different viewpoint may focus on light censorship and certain websites, as per a defined list of unacceptable material, should be restricted or penalties enforced (as per the private sector) for procrastinating university resources. The problem however, materialises in auditing what is acceptable and what is not. As evidenced above, the poor sophistication of the on-line discussion censorship software was not conducive to academic study. Neither is a censorship device that restricts access to websites that have common sexual terms within them (for example www.sussex.co.uk). Censorship should be appropriate for the circumstances; it should not stifle academic debate but it should prevent access to Internet sites that are otherwise undesirable.'

The issues are complex but the consequences of excessive control over the use of the Internet for learning and teaching in higher education are likely to be severe. Higher education should tread carefully. 


\section{References}

Barnett, R. (1992). Improving Higher Education. Buckingham. Society for research into Higher Education and Open University Press.

Charlesworth, A. (1997) Educating the User, Training the Administrator.

http://www.ukoln.ac.uk/services/elib/papers/other/copyright/session4/ [Accessed on 20/06/01]

Corlett, S. (2001) Special Educational Needs and Disability Bill. [Available at http://www.skill.org.uk/SEN Disability.htm] [Accessed on 22/06/01]

Daniel, J.S. (1996). Mega-Universities and knowledge media. London. Kogan Page.

EU (1999) EU Directive on the harmonisation of certain aspects of copyright and related rights in the information society. OJC 180 25.6.1999.

Flint, D. (1998). If you can't say something nice, don't say anything- defamation, libel and civil liberties on the Internet. Business Law Review, 19(12) pp. 279-292

Flint, D. (2001) No cash for cache - the EU Copyright Directive. Business Law Review, 22(1) pp. 3-5.

Lawrence Godfrey v Demon Internet, (1999) All ER 342

Hannan, A. and Silver, H. (2000). Innovating in higher education. Buckingham. Society for Research into Higher Education and Open University Press, pp.144

HEFCE (1999a) Providing public information on the quality and standards of higher education courses HEFCE Circular 99/61 (Report by Segal Quince Wicksteed) http://www.hefce.ac.uk/learning/Quality/ [Accessed on 27/06/01]

HEFCE (1999b) Teaching Quality Enhancement Fund. http://www.niss.ac.uk/education/hefce/pub99/99_48.html [Accessed 27/06/01] HEFCE (2000) Rewarding and developing staff in higher education. http://www.hefce.ac.uk/Pubs/HEFCE/2000/0056/0056.doc [Accessed on 27/06/01] Kennedy, D. (1997). Academic duty. Massachusetts. Harvard University Press Larson, W. J. (1998). Essentials of Human Embryology. New York. Churchill-Livingstone Laurillard, D. (1995). Multimedia and the changing experience of the learner. British Journal of Educational Technology 26 (3), pp. 179-189. 
McMurray, D. (2000). The importance of 'goodness of fit' between organisational culture and climate in the management of change: a case study in the development of online learning. Alt-j 9(1) pp. 73-83

McMurray, D. and Dunlop, M. (1999). The collaborative aspects of online learning: a pilot study. Southern Cross University. Available at http://ultibases.rmit.edu.au/Articles/online/mcmurry1.htm [Accessed on 04/06/01]

RADAR: the disability network. http://www.radar.org.uk

Sangster, A. (1992). Computer-based learning in UK accounting education: to support or to supplant? British Journal of Educational Technology. Vol. 23 (2) pp. 136-146.

Scott-Bayfield, J. (2001) Defamation update (June) Solicitors Journal 145 (21) pp. 501-503

Shephard K.L. (2001). Submission of student assignments on compact discs: exploring the use of audio, images, and video in assessment and student learning. British Journal of Educational Technology. 32 (2) pp. 161-170.

Strowel, A. (2000). The liability of online service providers. In Stamatoudi, I. and Torremans, P. Copyright in the new digital environment: the need to redesign copyright. (Perspectives on intellectual property). Sweet and Maxwell, pp. 131-162

Surry, D. W. (2000). Strategies for motivating higher education faculty to use technology. Innovations in Education and Training International. 37(2), pp. 145-153.

QAA (2001) Handbook for Academic Review http://www.qaa.ac.uk/public/acrevhbook/intro.htm [Accessed on 27/06/01] 